\title{
Examining the physical environment of Ghanaian inclusive schools: how accessible, suitable, and appropriate is such environment for inclusive education?
}

The extent to which inclusive schools can physically and pedagogically include children with disability and special educational needs or otherwise is also identified to depend largely on the physical environment. This descriptive, mixed methods study reports empirically-driven data on the nature, accessibility, suitability and appropriateness of the physical environment of inclusive schools, and how these impact inclusive education. A purposively selected sample of 164 inclusive teachers, with wide-ranging teaching experience was surveyed through a questionnaire. Observation data were also collected on aspects of the physical environment to complement the survey data. Study findings revealed that the physical environment of most 'inclusive schools' was of a poor quality, less accessible for children with physical and other sensory motor disability, and less suitable for school activities, including games and other physical education activities for all children. Teachers, therefore, called on the Government and the Ghana Education Service to urgently make changes to ventilation systems, decorations and colour in inclusive schools. They also highlighted the need for good architectural designs to facilitate effective natural and artificial illumination in classrooms and buildings, modification of facilities, and redesigning the physical landscape of schools to promote accessibility and use for all children, regardless of disability. The findings have implications for universal design environments for inclusive education.

Keywords: physical environment; inclusive education; inclusive schools; disability; accessibility; mixed methods 


\section{Introduction}

With the increasing trend towards educational reform, policy making and change practice, education systems and governments worldwide have identified Inclusive Education (IE) as the principal vehicle for educating all learners regardless of disability and/or Special Educational Needs (SEN). The educo-socio-political and economic basis for IE is to address the challenges of access, quality and equity in education practice, policy and provision. Philosophically, IE articulates that all learners are capable of learning and participating in educational and social experiences in a safe and scaffolding environment (Ackah-Jnr 2016). Thus, when children with disability especially, are provided with appropriate attention, supports, and resources in highquality, age-appropriate, general education classrooms and environments, they are more likely to succeed (Allen and Cowdery 2015, Cologon 2014, Foreman 2011, Foreman and Arthur-Kelly 2016, Mitchell 2010). Inclusive education, as an evolving and transformative practice ensures that, the hitherto excluded, marginalised, discriminated and disadvantaged learners exercise their educational right. Overall, it rationalises the need for educating all, regardless of disability and SEN. For Slee (2013), IE challenges the notion of business as usual for schools globally. Consequently, the move towards enhanced IE practice implementation will inadvertently bring aboard the inclusion-ship many diverse learners, liberating, empowering and enabling them to rise and realise their potential, and to make meaningful contributions to self and society generally. Internationally, many countries including Australia, Canada, USA and South Africa have progressively acceded to the clarion call for the recognition, adoption and implementation of IE as a change and best practice. This is mainly based on its empirical benefits such as academic and social outcomes and the rationale such as human rights and social equity (Foreman 2011, Smith et al. 2012, Cologon 2014, Mitchell 2010, Slee 2013, Ackah-Jnr 2016, 2017), as well as the supporting conventions 
and declarations, including the Salamanca Statement (1994), the Dakar Framework for Action (2000) and UN Convention on the Rights of Persons with Disability (UNCRPD, 2006). Therefore, IE practice has become a wind of change and positive pressure exerting influence and driving education systems in the global North and South or in both developed and developing countries.

As a middle-income developing country, Ghana has similarly recognised IE and has made several commitments to its practice. Influenced by the aforesaid drives, as well as national legislative framework and policies including the Education Act 1961, Education Act 2008 and more recently, IE Policy 2015, Ghana has also established inclusive pilot schools, to complement regular schools to educate children with disability and SEN (Ackah-Jnr 2016). The inclusive schools support the operationalisation of Ghana Government's policy objective to implement IE, which aims to provide [accessible and] equitable educational opportunities for all children with mild SEN in mainstream schools and full enrolments of hard-to-reach and out of school children (Ministry of Education [MoE] 2012). While teacher preparedness and effective curriculum have been identified particularly as key factors that enhance student learning and performance and IE practice in Ghana (Kuyini 2014, Ackah-Jnr 2014), the quality of the physical environment of [inclusive] schools, where students learn, interact and socialise with other peers, or they are taught, is often overlooked. Nonetheless this is not peculiar to the Ghanaian context, as Loreman $(2007,28)$ acknowledges succinctly that, "there is too often the ignoring of the physical environment in favour of issues which are perhaps more intellectually exciting" to researchers. As such, the physical environment is crucial to IE implementation.

The study's central thesis is to ascertain the extent to which the physical environment supports or hinders IE. Whilst the barriers to IE may take many forms and 
are multi-faceted, but are cross-culturally and cross-contextually similar to a larger extent, the physical environment of schools is considered a critical implementation factor influencing IE (Pivik, McComas, and Laflamme 2002, Smith et al. 2012, Lewis and Doorlag 2006). There is much research reinforcing that the quality of the physical environment significantly affects student learning and achievement (Cheryan et al. 2014, McCreey and Hill 2005, Tanner 2008, Weinstein 1979) and student attitudes (Sapon-Shevin 2007, Weinstein 1979). The physical environment comprises the classroom and its furnishings, but more broadly, it denotes the school building and all its contents including physical structures, infrastructure, furniture and the site on which a school is located and the surrounding environment with which all children may come into contact (World Health Organization 2004). On the one hand and from an inclusive orientation, the physical environment connotes flexible and safe school buildings and facilities, adjusted to students' aesthetics as well as to participatory teaching [and learning], and the 'feeling' of the school, the extent of social connectedness and respect for differences, styles of communication and conflict management at school, and care for the well-being of students as well as school staff (Simovska 2004). It is thus intertwined with elements of the social environment, and it impacts the affective, behavioural and cognitive functions of children and teachers in inclusive schools.

The physical environment of schools thus defines whether all children are physically, pedagogically and functionally included or excluded from school programs. To promote IE, new schools are being designed to be accessible, barrier-free, welcoming, and generally more supportive of children with disability, especially those with physical disability. In Ghana, however, the physical environment of most schools implementing IE appears to be user-friendly mostly for children without disability.The architectural design and physical layout of most school buildings are still tailored to fit 
and fix students without disability. Elsewhere, Australia, Elkins $(2005,46)$ noted similarly that little account is taken of individual differences in students, and not much attention is given to school design as a factor for successful IE. Often children with disability in Ghana, especially those with physical and neuromotor disability struggle to fit in or face daily challenges using school facilities and navigating school settings and other public buildings. A critical analysis of the policy guidelines on the planning and design of school environment and infrastructure (e.g., Education Act 1961, Education Act 2008, IE Policy 2015), shows that they have not been fully actioned to support the effective use of facilities and other aspects of the physical environment by children with disability, which potentially affects IE. The Ghana Disability Act 2006 (Government of Ghana 2006), recognises that for persons with disability to effectively use school facilities, equipment and other aspects of the physical environment, and hence promote the IE agenda,

the Minister of Education shall by Legislative Instrument designate schools or institutions in each region which shall provide the necessary facilities and equipment [and barrier-free physical environment] that will enable persons with disabilities to fully benefit from the school (s.715.17, emphasis added).

The Ghana Education Act 2008 (Government of Ghana 2008)further mandates that

District Assemblies and heads of institutions shall ensure that designs for schools are user-friendly for children with special needs and disability, and institutions, including regular schools that deliver education to children with special needs shall improve upon existing infrastructure and provide for additional facilities where necessary (Education Act 778), p.5, emphasis added).

Inherent in the Standards and Guidelines for the Practice of Inclusive Education in Ghana 2015, Standard 1, are the provisions for enabling access to schools for children with disability, deemed also to benefit children without disability. Critically, the 
recommended

inclusive education standards shall satisfy anyone who is hindered from participating successfully in learning [environment] as a result of obstacles put in their way by the siting of the school, design of buildings, materials, arrangement of out- or inside space, attitude of staff, equipment and materials...and pedagogy (MoE 2015b, 6).

In addition to these legal provisions, the IE policy (MoE 2015a) has the objective to redefine and augment education and support services that are responsive to the needs of all children, within the context of universal design and child-friendly schools, and overall, to increase participation and educational access for children with SEN. To achieve this policy goal, the physical architectural designs and environments of existing schools need to be modified or adapted, while ensuring also that all new school physical designs and constructions enhance opportunities for persons with SEN.

However, while nationally the legal directives and policies supporting the restructuring and transformation of schools to make them more inclusive are wellintentioned, it is generally evident that most schools practising IE operate in 'unchanged physical environment and educational facilities'. Thus, a further look at inclusive schools indicates a seemingly lack of adaptation and modification of the physical environments, including architectural designs and facilities to meet the needs of children with disability and SEN. There are problems of stairs, narrow doorways, inappropriate seating, rigid classroom designs and school compounds, which generally affect access, student learning, participation and achievements or engagement. Further, whilst extensive research is available in the Ghanaian context on teacher attitudes towards IE (Gyimah, Ackah-Jnr, and Yarquah 2010, Ackah-Jnr 2010, Obeng 2007, Ackah-Jnr 2017), research on the physical environment of regular schools practising IE has particularly attracted little attention. The present study accordingly examines the 
physical environment of schools implementing IE and how this impacts successful practice. This research contributes to the knowledge on the physical environment of schools, by highlighting the nature, accessibility, suitability and appropriateness of such environment for IE. In doing so, this study is underpinned by five research questions:

1. What is the nature of the physical environment of inclusive schools?

2. To what extent is the physical environment of inclusive schools accessible to all children?

3. To what extent is the physical environment suitable for physical activities?

4. To what extent is the physical environment appropriate for inclusive education?

5. In what ways can the physical environment of inclusive schools be improved?

\section{Physical environment of inclusive schools}

Since the extensive review of the research on the importance of the physical environment of schools (Weinstein 1979), other researchers have also increasingly explored the impact of various dimensions of the physical environment on the education of all children generally, and more specifically children with disability (Cheryan et al. 2014, Engelbrecht 2003, Higgins et al. 2005, Jin, Yun, and Agiovlasitis 2017, Pivik, McComas, and Laflamme 2002, Tanner 2008, Lewis and Doorlag 2006). Research investigations show that the nature of the physical environment of IE schools influences teacher and student behaviour, student learning and achievement (Cheryan et al. 2014, Guardino and Fullerton 2010, Tanner 2008, Weinstein 1979), physical access (Pivik, McComas, and Laflamme 2002, Winter and O'Raw 2010), physical activity participation (Jin, Yun, and Agiovlasitis 2017, Pivik, McComas, and Laflamme 2002) and feelings of belonging and acceptance in IE schools (Okyere and Adams 2003, Sapon-Shevin 2007). School environments that support IE: reduce unnecessary exclusionary barriers, and also increase presence, participation and achievement of all learners (e.g., Booth, Ainscow, and Kingston 2006). In the light of this and for students 
with physical and mobility disability and other sensory disability especially, IE schools should avoid architectural elements such as flight of stairs to rooms and slippery outdoor surfaces, as well as heavy doors and narrow doorways (Winter and O'Raw 2010, Lewis and Doorlag 2006), which may induce fatigue and exclusion or minimise use of facilities. The presence of these elements constitutes physical barriers to IE. Hence, the physical environment needs to be architecturally accessible and suitable /usable so that no learner is denied equitable education and social experiences.

Previous research indicates that classroom management is an integral part of a carefully planned physical environment (Okyere and Adams 2003, Smith et al. 2012, Allen and Cowdery 2015), influencing how teachers and students feel, think and behave in IE schools (Guardino and Fullerton 2010, Weinstein 1979, Weinstein, Mignano, and Romano 2011). Classrooms that are barrier-free and arranged effectively may foster free movement of children with disability between desks or tables, and to the general areas of the school. For Elkins (2005) at the classroom physical access needs to be the first consideration for effective IE. In well-planned IE classrooms, there is effective seating arrangement and spacing (Lewis and Doorlag 2006, Smith et al. 2012), and instructional materials are placed within the reach of all children, and adequate storage spaces are also created for special equipment such as magnifying devices, crutches and adapted keyboards for computers (Lewis and Doorlag 2006). Bookshelves and bulletin boards are also conveniently located to facilitate their use by students with disability, and there are adequate spaces in the general areas of the school to accommodate all students (e.g., classrooms, hallways, exits and washrooms). Following the need to create inclusive environments, Okyere and Adams (2003) articulated that effective classrooms must have sufficient spaces for all children to move around or functionally participate in activities, especially if there are children with physical disability . 
Additionally, the safety and comfort of the inhabitants of schools is identified as another key dimension of an appropriate phyiscal environment that affect the feelings of belonging in IE settings (Sapon-Shevin 2007, Okyere and Adams 2003, Lewis and Doorlag 2006, World Health Organization 2004). For Sapon-Shevin (2007), IE schools are particularly comfortable when children with disability feel psychologically and emotionally safe, which engenders acceptance, participation and the recogniton of all children as individuals. Such schools are deviod of characterisation such as namecalling, ridicule and teasing or negative attitude projections. A carefully planned physical enviornment also enhances the psychological comfort of children and eliminates detrimental sensory reactions (Okyere and Adams 2003, Tanner 2008, Lewis and Doorlag 2006). Following this mentation, once all children get to school, their safety and comfort, and access to buildings and teaching and recreational areas should be guaranteed, if really schools are inclusive. When everyone feels safe and comfortable, learning may also be enhanced for all. Indeed, for Lewis and Doorlag (2006), eliminating architectural barriers e.g. small doorways and poor room spacing and layout, will ensure that children with disability are safe and can move freely in the school, which in turn, allows for more effective use of facilities. Consequently, schools that have elevators and ramps; wide doorways that allow wheelchairs to pass through, and; bathroom facilities (e.g., toilets and urinals) that are adapted or specially designed, are important for IE. Equally, in keeping with the philosophy of IE, schools should protect all children, and make them feel welcome and accepted, as they participate in the learning and social activities. Similarly, external and internal (chronic) noise impact classroom climate and comfort of children (Higgins et al. 2005). Because noise distracts students from their work or interfere with their ability to hear others speaking, it is 
essential to reduce unwanted environmental sounds or acoustics (Allen and Cowdery 2015, Higgins et al. 2005, Elkins 2005).

Further research evidence shows that an appropriate physical environment means that the conditions of classrooms are pleasant and appealing to all learners (Engelbrecht 2003, Tanner 2008, Weinstein 1979). When the classroom is comfortable and attractive, learning is likely to be enhanced. Many researchers (Cheryan et al. 2014, Engelbrecht 2003, Higgins et al. 2005, Lewis and Doorlag 2006) agree that classroom conditions such as temperature, ventilation, lighting and acoustics, are key factors that influence the learning and comfort of students and teachers in schools. In this light, Okyere and Adams (2003) noted that effective IE requires a nurturing environment, if all children are to feel belong and part of the classroom. Aesthetically pleasing classrooms may enhance the learning, comfort levels and health of all learners.

Two other critical components of the physical environment of schools, identified to impact IE practice are ventilation (Higgins et al. 2005, Lewis and Doorlag 2006) and lighting (Cheryan et al. 2014, McCreey and Hill 2005, Tanner 2008). Research shows that adequate ventilation prevents stuffiness in classrooms, enhancing the general comfort and well-being of children and teachers (Higgins et al. 2005, Lewis and Doorlag 2006). Ventilation or air-quality is considered a basic survival need. Adequate natural and artificial illumination has been identified as an important element of IE schools and classrooms, which makes teachers and students to feel comfortable during teaching and learning (Cheryan et al. 2014, McCreey and Hill 2005), while poorly lit classrooms causes students to feel a jet lag (Tanner 2008). A study that investigated the effects of school design on student outcomes (Tanner 2008) also found that students exposed to more natural light in their classrooms performed better than students exposed to less natural light. Inclusive classes that are well-light and free from glare are 
important for all learners, especially students with visual impairments since they may require improved lighting. As a critical characteristic of effective classrooms, good lighting (McCreey and Hill 2005, Lewis and Doorlag 2006) also fosters the general well-being of students and teachers who are usually confined to the classrooms for several hours per day. "Inadequate lighting controls can produce negative results, including eye strain, fatigue, decreased attention span, increased body temperature and, consequently, poor student/teacher performance" (McCreey and Hill 2005, 1). Light and colour are seen to affect learning and blood pressure of students in IE classrooms (Tanner 2008, Gaines and Curry 2011).

Colour signifies another essential aspect of the physical environment and aesthetic appeal identified to influence student learning and behaviour in inclusive settings (Engelbrecht 2003, Gaines and Curry 2011, Higgins et al. 2005, McCreey and Hill 2005). As a powerful design element, colour produces psychological and physiological reactions, and impacts student behaviour within the physical learning environment, hence functional colour applications are critical to the inclusion of students with disability (Gaines and Curry 2011). As light colours enhance illumination systems in inclusive classrooms (McCreey and Hill 2005, Meeks, Heit, and Page 2007), researchers (e.g., Smith, Neisworth, and Green 1978) have previously argued against the use of dark or bright colours for classroom walls. For Smith, Neisworth, and Green (1978) wall surfaces that have light tone colours, and not drab, function better as pleasant background for whatever is placed on them in classrooms. Different colours are considered stimulating. This varies across the age groups. While younger children prefer bright colours and patterns, adolescents prefer more subdued colours (Engelbrecht 2003). Maxwell (2000) also found that children thought colour was important and that they thought the colour of the walls in their school was uninviting 
and boring. Further, room decoration is important because it can affect the attractiveness of classrooms (Tanner 2008). Therefore, effective furnishings, pictures, posters and displays of education materials and equipment can enhance the visual appeal of inclusive classrooms and the engagement of all children.

\section{Conceptual and theoretical framework}

As noted, IE is seen mainly as a process of ensuring quality and equitable access, participation and engagement, as well as a process of change. Inclusive education aims at responding to the 'uniqueness' of individuals [and the variability within groups], and increasing their sense of presence, access, participation and engagement in schools (Hyde 2014, Booth, Ainscow, and Kingston 2006). While IE may have differing conceptualisations, interpretations and meanings or nomenclature, it is grounded primarily in eliminating (un)intentional barriers and changing the dynamics of schools that tend to restrict learning and social interaction opportunities for all learners, regardless of disability. In this vein, the physical environment of schools, where such learning and interrelationships develop, is crucial to IE, as it plays a key role not only in a functional sense but also in social, psychological, cultural and ethical dimensions.

As a study attempting to understand the impact of the physical environment on IE, it is premised on universal design (D'souza 2004, Story 2011, Ostroff 2011), a concept that originated from architecture and product development. Universal design (UD) has historically emerged in nations, with significant cultural differences, but the movement has more apparent similarities than differences as they transcend national laws, policies and practices (Ostroff 2011). It was first used and promoted in the United States by Mace in 1985 to articulate a design approach that could be utilised by a wider range of users, though forms of it were prevalent earlier in European countries e.g. Norway (D'souza 2004, Story 2011). Worldwide, two forces precipitated the evolution 
of UD: key legislative measures that included specialised requirements to accommodate people with disability, and non-regulated market-driven responses to an aging society, primarily relating to products (Ostroff 2011). It thus focused on accessibility for people with (physical) disability, or wheel chair access.

As a dominant term, UD has been used interchangeably with concepts such as design-for-all and barrier-free design, and applied in business and society, but it gained wide application in education systems from the 1990s (Ostroff 2011). Universal design means accessibility that goes beyond barrier-free design, and broadly speaking, it connotes the design of products, environments, programs and services, to be usable by all people, to the greatest extent possible, without the need for adaption or specialised design (United Nations [UN] 2006, Story 2011). It aims to ensure environments are both accessible and usable. Accessibility is a relative concept, implying that accessibility problems should be expressed as a person-environment relationship. Thus, accessibility is the encounter between the person's functional capacity and the design and demands of the physical environment (Iwarsson and Ståhl 2003). While it focuses more on mobility issues, accessibility is also considered an umbrella concept for all parameters that influence human functioning (Ostroff 2011). An accessible environment is one where individuals with any disability can 'function independently'. Usability implies that a person should able to use, i.e. to move around, be in and use, the environment 'equally' with others (Iwarsson and Ståhl 2003) or the accomplishment of functional requirements. However, accessibility is a necessary precondition for usability. Usability embraces perceptions of how well the design of the environment enables functioning, performance, and well-being (Iwarsson and Ståhl 2003).

Universal design is considered the best approximation of an environmental facet to the needs of users, and is a process rather than a definite result (Iwarsson and Ståhl 
2003). It is therefore an overarching paradigmatic shift in design thinking — from a lack of awareness of the restrictive and emancipatory roles that design plays, to an awareness and elimination of environmental barriers, and beyond that to a concept of designing, at the outset, for the widest range of potential users (Ostroff 2011). While UD developed within an evolving concept of disability, it emphasises the idea of equity. Hence, it is considered a human-centred and right-based approach, in search for creative and more inclusive solutions and designs, beyond the ordinary provision of specialised designs. Following, UD ensures that the physical environments of schools, including buildings and facilities, and architectural designs are accessible, aesthetically pleasing, functional and efficiently usable by all, reinforcing the need to proactively include those with disability in the broader conceptions and provision of education and environments, and not an afterthought, to warrant later accessibility strategies or accommodations. The theoretical positioning of UD, therefore, supports the view that inclusive physical environments will benefit all learners, and promote their safety and health.

Seven key principles underline UD that ensure specific designs use are maximised (Ostroff 2011, Story 2011). These guiding principles support the vision of IE: (1) Equitable use: The design is usable and marketable to people with diverse abilities; appeals to and offers everyone a comparable and non-stigmatising way to participate. Hence, seating arrangement should simulate easy movement, or participation in class activities, (2) Flexibility in use: The design accommodates a wide range of individual preference and abilities, allowing for multiple ways of doing things or adaptable to make designs universally usable, (3) Simple and intuitive: Use of the design is easy to understand, regardless of the user's experience, knowledge, language skills or current concentration level. Hence, it should eliminate unnecessary complexity, provide effective prompting and feedback or scaffolding, (4) Perceptible information: 
The design communicates necessary information to the user, regardless of ambient conditions or sensory abilities. Designs thus provide for multiple modes of output (pictorial, verbal, tactile) for presenting essential information, (5) Tolerance for error: The design minimises hazards and the adverse consequences of (un)intentional actions. It should make it difficult for users to make a mistake; but if users do, errors should not result in injury to the person. Hence, hazards are eliminated in schools to ensure the safety of all children, (6) Low physical effort: The design can be used efficiently and comfortably, with a minimum fatigue, or lessens strain and overexertion. In schools, heavy doors that require repetitive use should be eliminated, and (7) Size and space for approach and use: Appropriate size and space is provided for approach, reach, manipulation, and use regardless of body size, posture, or mobility. In essence, classrooms should have adequate spaces to accommodate children with physical disability to use assistive devices or personal assistance. UD, overall, seeks to make IE schools, accessible, usable, safe, simple and tolerable and accommodating for all.

\section{Research design and method}

This study, a descriptive-orientated, mixed methods research, explored essential dimensions of the physical environment of IE pilot schools. The study design utilised a survey, combined with written responses and semi-structured observation concurrently to gather both quantitative and qualitative data. The survey was deemed useful for obtaining factual information about the physical environment, which provided a better understanding and measurement of how the study variables were naturally distributed. It enabled the collection of cross-sectional data to describe existing conditions or identify standards against which existing conditions can be compared (Cohen, Manion, and Morrison 2011, Neuman 2014). On the other hand, the semi-structured observation was conducted to ensure that critical elements of the physical environment were recorded or 
checked against most aspects of the survey items. The descriptive mixed methods thus ensured the collection of quantitative and qualitative data complementarily for the effective data analysis (Teddlie and Tashakkori 2009, Creswell 2014).

\section{Research context and participants}

This research is part of a larger study that investigated the implementation of IE. One hundred and sixty-four teachers, selected from 29 inclusive pilot schools located in the Eastern, Greater Accra and Central Regions of Ghana, constituted the study sample. Purposive sampling was adopted in selecting the schools and teacher participants. This was done to capture and maximise variation in the physical environment. According to the Preliminary Education Sector Performance Report, the inclusive schools were located in southern Ghana and were deemed to be well resourced (MoE 2008). The inclusive schools educated children with at least one of the disability categories ${ }^{1}$ in Ghana. At the time of the research, each region had three districts with inclusive pilot schools. Each district had three or four inclusive pilot schools for educating children with and without disability. The inclusive schools had trained regular school teachers, of which $34.1 \%$ had a degree in education and 38 (23.2\%) diploma in education, whereas a few teachers $(1.2 \%)$ had a master's degree in education. Many teachers $(41.5 \%)$ had a minimum of 3-year certificate ' $\mathrm{A}$ ' in education, but were undertaking various courses leading to diploma and degree in education. Through purposive sampling procedures, $64(39.0 \%)$ male and $100(61.0 \%)$ female teachers were selected from the 29 inclusive pilot schools. Approximately 57.3\% of the teachers aged between 25 and 35 years, and $17.1 \%$ were 46 years and above. Most teachers $(57.3 \%)$ had 
between 1 to 5 years of teaching experience, whereas $40(24.4 \%)$ had 11 and above years of teaching experience. These teachers were generally deemed to have rich insights and knowledge about IE. Table 1 presents the demographic characteristics of the study participants.

[Insert Table 1 near here]

Table 1. Demographic characteristics of teachers at the selected inclusive schools

\section{Research instrument and data collection}

The researchers used mainly a survey questionnaire, with a few open-ended questions, as the data gathering instrument to collect both quantitative and qualitative data for the study. Observation data were also collected from seven schools the nature of the physical environment to complement the survey data. The research instruments were designed based on the available theoretical and empirical literature, and the aim was to ensure that the content aligned with the research questions and objectives. The instruments were piloted, and participant feedback was factored into the final instruments that were administered, enhancing the credibility of the data collected. This mixed methods study thus combined survey and observation, administered concurrently, which facilitated concurrent data analysis and integration for interpreting the results (Creswell 2014, Teddlie and Tashakkori 2009).

Aside from the demographic section, the questionnaire had four sections. While the first section elicited responses on the nature of the physical environment, the second section was on the accessibility and suitability of the physical environment of IE schools. The third and fourth sections focused on the appropriateness of the physical environment and measures to improve such environment for IE respectively. Both 
survey and observation data were personally collected from teachers. The questionnaire consisted of Likert scale formatted-items on the nature of the physical environment, with scale values ranging from 1 = Very Poor, $2=$ Poor, 3 = Good, and 4 = Very Good. There were also dichotomous questions on the accessibility of the physical environment to all children and the suitability of the physical environment for physical activities, which elicited "Yes" or "No" responses, while teachers supplied comments to justify their responses. Teachers also provided "Yes" or "No" responses on the overall appropriateness of the physical environment for IE practice and additional comments. They supplied only written comments to the research question on improving the physical environment. Initially, the data collection involved 134 teachers, but a further data collection using the same survey and observation protocol, intended to capture more variability in the physical environment, included an additional five schools and 30 teachers, making a total of 29 schools and 164 participants.

Ethical considerations (Cohen, Manion, and Morrison 2011, Neuman 2014) were central to this research. Participants consented to participate in the study, which fostered effective collaboration during the data collection. Headteachers and teachers of the participating schools were well informed about the nature, process, purpose and use of the research. Participants were also given the assurance of anonymity and confidentiality of their responses, and an open window for anyone to withdraw from the research at any stage if necessary. While the pursuit of this study aims to contribute to knowledge on IE, it guarded against potential costs to teachers and the participating schools such as loss of privacy and democratic freedoms generally (Neuman 2014, Cohen, Manion, and Morrison 2011). With appropriate permission from the Ghana Education Service, the gatekeepers of research, and headteachers and teachers of the 
selected schools, effective rapport building ensued during the data collection, and 164 teachers participated voluntarily in this study.

\section{Results and discussion}

This section presents and discusses the findings of the study. Whilst some physical environment of schools supported student involvement, participation, and learning, others were challenging for the daily accessibility, use and functioning of children, especially those with disability. Teacher responses to the first research question on the nature of the physical environment of IE schools, expressed in frequencies and percentages, are shown in Table 2.

[Insert Table 2 near here]

Table 2. Physical environment of inclusive schools $(\mathrm{N}=164)$

\section{The nature of physical environment of inclusive schools}

From Table 2, "ventilation in classrooms and other buildings" was the single dimension of the physical environment that teachers reported to be generally adequate. As a basic survival need, adequate ventilation was also seen as a critical element, which enhances the general comfort of teachers and students, and student learning. While 89 (54.3\%) teachers felt that the ventilation in most IE classrooms and buildings was sufficient and of good quality, $75(45.7 \%)$ teachers had an opposing view. Adequate ventilation, whether natural and artificial, was perceived to essentially prevent stuffiness and heat in classrooms, creating conducive learning environments for all. However, for nearly $46 \%$ of teachers, ventilation in inclusive classrooms and buildings was inadequate, which made the learning environment less comfortable. From the observation data, whereas some schools in particular had excellent ventilation systems, whether natural or artificial, others did not have such systems. Some schools thus by default were poorly 
ventilated due to their architectural designs. Yet ventilation is considered a critical classroom condition affecting the comfort of students and teachers (Cheryan et al. 2014, Higgins et al. 2005, Tanner 2008, Lewis and Doorlag 2006). The perceived poor ventilation is likely to affect teacher output, the general well-being and concentration levels of all children regardless of disability during instructional hours.

Ninety-four $(57.0 \%)$ teachers perceived the natural and artificial illumination in some classrooms and other buildings to be insufficient for all learners. Most schools had no artificial lighting systems, but relied more on natural lighting (daylight), which usually depends on the prevailing weather condition and the architectural make-up of classrooms. Generally while some schools had enhanced lighting systems and were well-lit, it was observed that the architectural designs of some schools (e.g., small windows or windowless classrooms) prevented adequate natural lighting in classrooms. Such inadequate lighting systems especially, could affect children with low visual impairment who needed enhanced lighting in order to participate in learning activities. This finding is contrary to previous research that found that good lighting, natural or artificial in inclusive classroom enhances the well-being of or makes students and teachers to feel comfortable (Tanner 2008, Lewis and Doorlag 2006). Insufficient lighting has been identified to result in negative outcomes, including excessive eye strain, decreased attention and poor student performance (McCreey and Hill 2005). In addition, poorly lit and windowless classrooms can also cause students to experience a daily form of jet lag (Tanner 2008). The results of the current study thus highlights the need to improve the general lighting systems of IE schools, and it is important that natural light is also maximised and supplemented by artificial lighting.

Effective seating arrangement was seen to enhance teaching and learning in IE schools. From the data, $92(56.1 \%)$ teachers felt the seating arrangement in IE classes 
was poorly done, while $72(43.9 \%)$ reported that the seating arrangement in IE classes was effectively done, which enhanced the participation of all children in class activities. For most teachers, the seating arrangement was rigid or fixed, and this hindered the full participation and involvement of all children in class activities, or functionality and usability of spaces. Although some teachers may be less knowledgeable about arranging the classroom effectively to maximise learning and activity participation, nonetheless most teachers attributed the poorly arranged or ineffective seating arrangement mainly to the architectural designs of schools. Thus, the architectural designs of some classrooms were seen to limit flexibility in the seating arrangement for learners and for multiple purposes. As Higgins et al. (2005) identified, since different room arrangements serve different purposes, it is necessary for classrooms to have some degree of flexibility of use. But some IE schools in this study operated in traditionally rigid classrooms, which were not adapted to suit the needs and use of all children, regardless of disability, or to reflect the tenets of IE, especially universal design. Effective organisation of IE classes, particularly seating, is important to meet the diverse needs of all children, especially those with disability (Higgins et al. 2005, Okyere and Adams 2003, Smith et al. 2012). Modification of the classroom, especially seating arrangements, increased academic engagement and decreased disruptive behaviour (Guardino and Fullerton 2010).

Decorations, wall paintings and the colour of some IE schools were perceived to be of poor quality. Many teachers, $98(60.0 \%)$, reported that the colour of some classroom walls and paintings were dull. The researchers also observed that in many schools, the colour of classrooms and decorations was either fading, and there was limited display of educational materials related to children's learning. These classrooms were found to be not attractive enough and appealing to all children generally. This 
finding is contrary to the admonition of Smith et al. (1978) that wall colours must serve as pleasant backgrounds in inclusive classrooms. Previous research shows that colourful decorations and paintings in schools generally enhance teaching and learning (Engelbrecht 2003, Higgins et al. 2005), and some children found the colour of the walls of their classroom uninviting (Maxwell 2000). Colour as a critical aesthetic element, influences student learning and behaviour (Gaines and Curry 2011, McCreey and Hill 2005). This implies that inclusive schools that have well-decorated classrooms, with quality and appealing colours, paintings and pictures, and effective display of educational materials, are more likely to stimulate learning and affective displays. A significant number of teachers, $120(73.2 \%)$, noted also that some inclusive classrooms limited the use of facilities like bookshelves, notice boards and instructional materials by all children. This finding reveals that children with disability were unable to use such facilities effectively, and in most instances, they had to depend on their peers for support. While peer support is instrumental to inclusive practice (Smith et al. 2012, Allen and Cowdery 2015), all children, especially those with disability need to be empowered to become effective users of school facilities. It was apparent from the observation that bookshelves, chalkboard, wall charts and other instructional materials in inclusive schools were usually not placed within the reach or height of some children, which limited their accessibility or use. Thus, the nature of such facilities did not support the equitable use principle of universal design.

Interestingly, one hundred and four (63.4\%) teachers were of the view that most IE schools did not adequately foster the safety and comfort of all children due to the location and that some children with disability were also discriminated against or encountered subtle ridicule and teasing from peers without disability. Only 60 (36.6\%) teachers reported that IE schools were safe and comfortable for all learners, and devoid 
of negative attitude projections. Unsafe and uncomfortable schools, with its attendant negative attitudes, pose challenges to both teachers and children, and IE generally. This finding indicates that most IE schools in this study did not meet IE policy objective of Government of Ghana: "to ensure that the learning environment is free from discrimination, safe and friendly for all children within the school” (MoE 2015a). For Sapon-Shevin (2007), IE environments that are especially comfortable, make children with disability to feel psychologically and emotionally safe, which engenders acceptance, participation and recogniton of all children, and are also deviod of characterisation such as name-calling, ridicule or teasing. Importantly, World Health Organization (2004) and Lewis and Doorlag (2006) noted that IE environments must primarily ensure the safety of their inhabitants. In support of this assertion, Winter and O'Raw (2010) noted also that a truly inclusive school needs to be safe for all students, including those with physical and sensory disability. As also evident from the observation, some IE schools were isolated from the community, like the traditional segregated special schools. As we move towards more IE, it is important to 'desegregate' IE schools in order to avoid the 'induced gaze syndrome' that society usually project towards schools that are isolated or located at the fringes of their neighbourhood or community.

One hundred and fourteen $(69.50 \%)$ teachers agreed that the physical environment of IE schools did not adequately foster free movement of children with disability, but 50 (30.5\%) disagreed that children with disability especially those with mobility problems experienced difficulties moving in and out of the school compound. It was observed that there were no access ramps to most buildings; most schools had the traditional 'front' stairs to classrooms, while the topography of some inclusive settings was stony and hilly, which presented additional difficulty to children with physical 
disability with respect to their daily movement to and from, and within the school and use of facilities. This finding counters the view that inclusive environments must be welcoming and barrier-free for all children, and also does not mirror the expectations and guidelines for IE in Ghana, Standard 1, which aims to provide access to all schools (MoE 2015b). Subsequently, the endorsed objective of promoting the "spirit of a barrier free learning environment for all learners in both public and private schools", however remain a challenge for those implementing IE (p.6). It is thus important to break down the barriers to free movement and create opportunities for everyone to participate and learn fully in their school.

School environments that manifest the philosophy of IE enhance increased access, participation and learning of all children, as well as the effective use of facilities. Sixty-seven percent of the teachers however reported that spaces in classrooms/ buildings and facilities in some inclusive schools, including washrooms did not effectively accommodate all children. Some classrooms and washrooms were found to be small; toilets and urinals were generally neither adapted nor modified to suit the needs of children with disability. Rather most school facilities were one-size-fits-all children, regardless of disability or SEN. These facilities did not support the key principles of usability and participation, guaranteed or deemed acceptable standards for learning environment and IE for all learners (MoE Standards and Guidelines, 2015). It was obvious from the observation that spaces in some IE classes were inadequate, which limited free movement for children with physical disability, and other general areas of some schools were also not large to accommodate all students. The limited spaces can also be due to large class size of some schools. This finding shows that spaces allowing freedom of movement for all students may enhance their participation 
and performance of all students (Tanner 2008). Spatial configuration and management of inclusive classes should thus cater for children's movement to use different spaces.

\section{Accessibility of the physical environment}

Accessible school environments are particularly important for all children, especially those with disability, enhancing student participation, learning and optimal well-being. To ensure that IE schools are accessible to all learners with a wide range of physical disabilities, appropriate adaptations and modifications are made in line UD principles (e.g., flexibility in use and low physical effort). The importance of intervening, including the removal of obstacles and barriers to participation in order to improve accessibility to the physical environment and equalise opportunities for all especially those with disability, is highlighted by UNCRPD (2006). Providing safe physical access to school buildings, classrooms and facilities, essentially ensures that all students can physically access the educational environment and be included also in all appropriate activities alongside their peers without disability (Winter and O'Raw 2010, Pivik, McComas, and Laflamme 2002). As reported by $61 \%$ of teachers in this study, the physical environment of most IE schools was seen to be less accessible to children with physical, neuromotor or sensory disability, and that these children generally encountered daily difficulties in their school life and functioning. The observation data revealed that in some schools, for example, classes were less spacious, doorways were not wide, and chairs and tables were not adapted or at the correct height for children with physical disability, which limit the effective use of such facilities. It therefore stands to reason that if children with physical disability cannot easily access key areas of IE schools and its facilities, nor have the freedom of movement and independence that maximise their learning, participation and social interaction with peers without disability, then, this is problematic. This situation may lead to further exclusion and 
alienation from school programs, routines and activities. Supporting this viewpoint and the need for the physical environment to accessible to all, Winter and O'Raw (2010) identified that a truly IE school is accessible to all students, including those with physical and sensory disability. From the observation data, it was further noticed that there were unmodified school facilities and no ramps, as well as inappropriate passageways and too little spaces between desks in many inclusive classrooms for children with disability, particularly those who use wheelchairs and crutches. For Pivik, McComas, and Laflamme (2002), a major barrier for most students with physical disability, is to 'physically' get into school and use facilities. While accessibility is not only in terms of ramps, automatic doors, and elevators, but includes all the features that make an environment user-friendly, significantly accessible, inclusive schools should benefit all persons with a wide range of disabilities, including physical, hearing, and visual impairments. This finding reinforces the need to modify the physical environment and infrastructure of schools in order to actualise Ghana's policy directives (e.g., Disability Act 2006, Education Act 2008, MoE Standards \& Guidelines 2015, IE Policy 2015) and actualise the principles of IE, especially universal design. As shown in Table 3, the physical environment was somewhat less accessible to children with disability.

[Insert Table 3 near here]

Table 3.Accessibility of the physical environment of inclusive schools

\section{Suitability of the physical environment for physical activities}

The suitability of the physical environment connotes the usability of aspects of the school compound, playground or surroundings for sports and other physical activities. Participating in physical activities is important for the health and psychological wellbeing of all children. Table 4 provides data on the suitability of the physical 
environment of IE schools for organising physical activities for all children. Whereas $60.0 \%$ of teachers found the physical environment to be less suitable for the effective organisation of most outdoor school activities such as games, sports, and other physical education activities for all children, $40.0 \%$ were of a contrary opinion. The findings clearly indicate that most teachers felt the school compound posed challenges to organising effective physical activities for children with disability. Thus, the suitability (usability) of the physical environment influenced physical activity participation for children with physical disability. Like other studies, students with physical disability often face difficulties participating in school activities (e.g., Pivik, McComas, and Laflamme 2002). The benefits of physical activity are well-documented, and significantly physical activity participation is identified to improve student academic performance, self-esteem and confidence, as well as promote a sense of belonging and acceptance and increased respect for individual abilities and differences, especially children with disability (e.g., Allen and Cowdery 2015, Jin, Yun, and Agiovlasitis 2017). As evident also from the observation data, the nature of the physical environment of some IE schools (e.g., hilly compound or stony park) limited the opportunities for all children to participate and engage in effective outdoor play, sports and games and to enjoy and benefit from such physical activities at the school. Jin, Yun, and Agiovlasitis (2017) identified that enjoyment of, and participation in school-based physical activity programs improves the general health of children, especially for children with disability. Physical education participation is recognised as a key curriculum focus in Ghana. There is, therefore the need for such inclusive environments to be modified to support physical activities for all children.

[Insert Table 4 near here]

Table 4. Suitability of the physical environment for physical activities $(\mathrm{N}=164)$ 


\section{Appropriateness of the physical environment}

An appropriate physical environment enhances access, learning, and participation of all children in inclusive schools. It also fosters functional use of the physical spaces and eliminates (un)intentional hazards and barriers, especially for children with disability. Such an environment is universally usable and safe, and may require the installation of special equipment, appropriate ventilation and lighting systems, modification of existing school structures and facilities that include the provision of ramps, wider doorways, and elevators, among others. Figure 1 shows the extent to which the physical environment is appropriate for IE. As seen from the Bar Chart, the physical environment of schools was perceived to be somewhat less appropriate for IE practice. The majority of teachers (128) held such a view, but only a few teachers (36) found the physical environment to be generally appropriate for IE. This finding was however not surprising as most regular schools transitioning to IE, use the traditional unchanged school buildings, facilities and environment. Hence, there was the absence of good architectural designs and physical layout, which posed challenges to IE. The observation data further revealed that some classrooms and buildings had inappropriate ventilation systems and aesthetic designs, and the compounds of some IE schools were generally not comfortable for all teachers and learners. In some specific cases, some IE schools were sited on hilly grounds, and a few schools were in storey buildings which complicated effective accessibility, usability and mobility of children with disability especially those with physical and sensory disability. In this situation how would children with physical disability easily access and functionally use classrooms and other buildings, and facilities where there are no elevators and ramps? This view was best captured in the comment of one teacher who stated that "our school is in a storey building, so it is difficult for the children with mobility problems to move about freely." 
[Insert Figure 1 near here]

Fig 1: Appropriateness of the physical environment of inclusive schools $(\mathrm{N}=164)$

\section{Improving the physical environment of inclusive schools}

Improving the physical environment of IE schools demands that physical, structural and architectural barriers that impede accessibility, usability and functioning: learning and social experiences of all children, are eliminated or minimised. In this direction, the physical environment should be accessible, suitable and appropriate for all children, considering their circumstances and needs, or enforce the principles of UD. Pivik, McComas, and Laflamme (2002) noted similarly that facilitating inclusive school environments, requires ensuring physical access, the opportunity for optimal learning and social experiences, and providing a nurturing climate. The physical environment should thus be 'humanising' for all. Qualitative evidence from teacher written responses revealed a number of measures that can be implemented to improve the physical environment of IE schools to make them more accessible, suitable and appropriate for all children. Thematic coding identified seven main suggestions: (1) improving ventilation in classrooms and buildings, (2) architectural changes to school buildings, including wider corridors and classrooms, widening doorways and installing access ramps near stairs, and modified school facilities e.g. washrooms, (3) effective illumination systems in classrooms and buildings, (4) efficient seating arrangement in classrooms, (5) improving decorations and colour in classrooms and buildings, (6) redesigning the physical landscape of IE schools to promote accessibility and organisation of recreational activities, and (7) Ensuring that the physical environment is safe, secure and comfortable for all persons. While all the suggestions are deemed necessary, most of the teachers perceived suggestions 1, 2, 3 and 4 as requiring urgent attention in the short term, but suggestions 5, 6 and 7 were considered critical in the 
medium term. The findings suggest that it is important that changes are made to physical environment so that involvement, participation, and access are somewhat straightforward for the majority of students, if not all, in order to maximise the education and social opportunities provided. For Elkins (2005), inasmuch as students with disability are concerned, a more radical approach seems warranted for the planning and design characteristics of inclusive schools.

\section{Conclusion and implication for inclusive education and practice}

Schools that create supportive learning and social environment for all children enhance IE. As noted, this study contributes to the research literature on the physical environment of IE schools. The study revealed that the physical environment impacts IE practice in terms of accessibility, learning and participation of children with disability, especially those with physical, mobility or sensory disability. Within the context of IE, the physical environment of most schools was found to be less accessible, less suitable for outdoor physical and recreational activities, and generally less appropriate for all children. Although some schools enabled IE, supporting its philosophy, principles and practice, and creating a moderating learning and social climate for all children, it was observed that if children with disability were to derive maximum benefits, this warranted architectural and structural changes in the physical environment. Schools that are accessible, suitable and appropriate, while particularly relevant for children with disability, also benefits all learners. Enhancing the physical environment will therefore transform the ways in which schools connect with all students, especially those with physical disability, pedagogy and practice. Despite the existing legal directives and policies, mandating that school designs, infrastructure and environment should be appropriate for all children, including those with disability and/or SEN, little has been achieved in this direction. On the basis of the results, the study recommends that the 
Ghana Government, MoE and GES adhere to and effectively action the supportive policies on IE, attract requisite resources to redesign and modify existing school facilities and environment and construct new schools that are more user-friendly. Of equal or perhaps greater importance, is the implementation of 'subtle' accessibility and usability interventions in schools, taking into account issues of affordability and technology, and diversity of inclusive settings. If Ghana is to strengthen its commitment towards IE, and realise the values of educating all children, then the physical environment should be considered as a critical dimension of successful practice. As evidenced by the tenets of IE, the physical environment of schools, comprising classrooms and buildings, infrastructure, furnishing and surrounding environment needs to be universally user-appropriate and user-friendly for all learners. The application of universal design principles will also help to minimise physical, sensory and cognitive barriers children with disability especially, experience in inclusive schools. While the sample for this research may be fairly large, to broaden our understanding of how the physical environment of schools impacts successful IE, there is the need for future studies to use a larger and more diverse sample to replicate this study, adopt mixed methods, involving questionnaire, interviews and documents, and also examine the effects of other dimensions of the physical environment such as the school climate and social environment on IE. 


\section{Acknowledgements}

Our appreciation is extended to the teachers who provided salient information, and to the Ghana Education Service for the permission that was granted for the research. We are also grateful to our anonymous reviewers and contributors for their critical comments.

\section{Disclosure statement}

There is no potential conflict of interest as known by the researchers.

\section{Funding}

This research was partly supported by the Ghana Government student research grant awarded to one of the researchers. 


\section{References}

Ackah-Jnr, Francis R. 2010. "Teacher characteristics as predictor of attitudes towards inclusive education in the Cape Coast Metropolis of Ghana." Ife Psychologia 18 (2): 35-47.

Ackah-Jnr, Francis R. 2014. "Implementation of inclusive early childhood education in Ghana: Enablers and barriers." AAARE-NZARE 2014 Conference, QUT, Brisbane.

Ackah-Jnr, Francis R. 2016. Teacher understandings and practice of inclusive early childhood education.

Ackah-Jnr, Francis R. 2017. Teacher attitudes towards inclusive education policy and change practice implementation in Ghana.

Allen, K. E., and G. E. Cowdery. 2015. The exceptional child: Inclusion in early childhood education. 8th ed. Australia: Cengage Learning.

Booth, T., M. Ainscow, and D. Kingston. 2006. Index for inclusion: Developing play, learning and participation in early years and childcare.

Cheryan, Sapna, Sianna A Ziegler, Victoria C Plaut, and Andrew N Meltzoff. 2014. "Designing classrooms to maximize student achievement." Policy Insights from the Behavioral and Brain Sciences 1 (1):4-12.

Cohen, L., L. Manion, and K. Morrison. 2011. Research methods in education. New York: Routledge.

Cologon, K. 2014. "Better together: Inclusive education in the early years." In Inclusive education in the early years, edited by K. Cologon, 1-26. South Melbourne: Oxford University Press.

Creswell, J. W. 2014. Research design: Qualitative, quantitative, and mixed methods approaches 4th ed ed. Thousand Oaks, Calfornia: SAGE Publications.

D'souza, Newton. 2004. "Is universal design a critical theory?" In Designing a more inclusive world, 3-9. Springer.

Elkins, John. 2005. "Inclusive education in Queensland: Where are we going and how will we get there?" Social Alternatives 24 (4):45-49.

Engelbrecht, K. 2003. The impact of color on learning. Chicago, IL: Perkins \& Will.

Foreman, Phil, ed. 2011. Inclusion in action. 3 ed. South Melbourne, Victoria: Cengage Learning Australia.

Foreman, Phil, and Michael Arthur-Kelly. 2016. Social justice principles, the law, and research, as bases for inclusion: An update. Department of Education \& Training Victoria.

Gaines, K. S., and Z. D. Curry. 2011. "The inclusive classroom: The effects of colour on learning and behaviour." Journal of Family \& Consumer Sciences Education 29 (1):46-57.

Government of Ghana. 2006. Persons with Disability Act (Act 715). Accra, Ghana: Parliament of Ghana.

Government of Ghana. 2008. Ghana Education Act (Act 778). Accra, Ghana: Parliament of Ghana.

Guardino, Caroline A, and Elizabeth Fullerton. 2010. "Changing behaviors by changing the classroom environment." Teaching Exceptional Children 42 (6):8-13.

Gyimah, Emmanuel K., Francis R. Ackah-Jnr, and John A. Yarquah. 2010. "Determinants of differing teacher attitudes towards inclusive education practice." Ghana Journal of Education Issues and Practice 2 (1):84-97.

Higgins, Steve, Elaine Hall, Kate Wall, Pam Woolner, and Caroline McCaughey. 2005. The impact of school environments: A literature review. London: Design Council. 
Hyde, Mervyn. 2014. "Understanding diversity, inclusion and engagement." In Diversity, inclusion and engagement, edited by Mervyn Hyde, Lorelei Carpenter and Robert Conway, 3-38. Australia \& New Zealand: Oxford University Press.

Iwarsson, S., and A. Ståhl. 2003. "Accessibility, usability and universal designpositioning and defnition of concepts describing person-environment relationships." Disability and Rehabilitation 25 (2):57-66. doi: 10.1080/dre.25.2.57.66.

Jin, Jooyeon, Joonkoo Yun, and Stamatis Agiovlasitis. 2017. "Impact of enjoyment on physical activity and health among children with disabilities in schools." Disability and Health Journal 11 (1):14-19. doi: http://dx.doi.org/10.1016/j.dhjo.2017.04.004.

Kuyini, A. B. . 2014. "Special education today in Ghana." Special Education International Perspectives: Practices Across the Globe 28:431-469 doi: 10.1108/S0270-401320140000028021.

Lewis, Rena B., and Donald H. Doorlag. 2006. Teaching special students in general education classrooms. 7 ed. Upper Saddle River, NJ: Pearson/Merrill-Prentice Hall.

Loreman, Tim. 2007. "Seven pillars of support for inclusive education: Moving from "why?" to "how?"." International Journal of Whole Schooling 3 (2):22-38.

Maxwell, L. E. 2000. "A safe and welcoming school: What students, teachers and parents think." Journal of Architectural and Planning Research 17 (4):271282.

McCreey, J., and T. Hill. 2005. " Illuminating the classroom environment." School Planning \& Management 44 (2): 1-3.

Meeks, L., P. Heit, and R. Page. 2007. Comprehensive school health education. 5th ed. Boston: The McGraw-Hill Companies Inc.

Ministry of Education [MoE]. 2012. Education strategic plan (ESP) 2010-2020: Strategies and work programme. edited by Ministry of Education. Accra, Ghana: Ministry of Education.

Mitchell, David. 2010. In Education that fits: Review of international trends in the education of students with special educational needs. Christchurch, New Zealand: University of Canterbury.

MoE. 2008. Preliminary education sector performance report. edited by MoE. Accra, Ghana: MoE.

MoE. 2015a. Inclusive education policy. Accra, Ghana: MoE.

MoE. 2015b. Standards and guidelines for the practice of inclusive education in Ghana. Accra, Ghana: Author.

Neuman, Lawrence W. 2014. Social research methods: Qualitative and quantitative approaches. 7 ed. Essex, England: Pearson Education Limited.

Obeng, Comfort S. . 2007. "Teachers' views on the teaching of children with disabilities in Ghanaian classrooms." International Journal of Special Education 22 (1):96102.

Okyere, B. A., and J. S. Adams. 2003. Introduction to special education: An African perspective. Legon-Accra, Ghana: Adwinsa Publications Ltd.

Ostroff, Elaine. 2011. Universal design: An evolving paradigm. In Universal design handbook, edited by Wolfgang F. E. Preiser and Korydon H. Smith. New York: McGraw Hill.

Pivik, J., J. McComas, and M. Laflamme. 2002. "Barriers and facilitators to inclusive education." Council for Exceptional Children 69 (1):97-107. 
Sapon-Shevin, M. . 2007. Widening the circle: The power of inclusive classrooms. Boston: Beacon Press.

Simovska, V. 2004. "Student participation: A democratic education perspectiveexperience from the health-promoting schools in Macedonia." Health Education Research 19 (2):198-207. doi: 10.1093/her/cyg024.

Slee, R. 2013. "How do we make inclusive education happen when exclusion is a political predisposition?" International Journal of Inclusive Education 17 (8):895-907. doi: 10.1080/13603116.2011.602534.

Smith, R. M., J. T. Neisworth, and J. G. Green. 1978. Evaluating educational environments. Columbus: Merill/Prentice.

Smith, T. E. C., E. A. Polloway, J. R. Patton, and C. A. Dowdy. 2012. Teaching students with special needs in inclusive settings. Boston: Pearson Education Inc.

Story, Molly Follette. 2011. Principles of universal design. In Universal design handbook, edited by Wolfgang F. E. Preiser and Korydon H. Smith. New York: McGraw Hill.

Tanner, Kenneth C. 2008. "Effects of school design on student outcomes." Journal of Educational Administration 47 (3):381-399. doi: 10.1108/09578230910955809.

Teddlie, C., and A. Tashakkori. 2009. Foundations of mixed methods research: Integrating quantitative and qualitative approaches in the social and behavioral sciences. Thousand Oaks, Calfornia: Sage Publications, Inc.

United Nations [UN] 2006. Covention on the Rights of Persons with Disabilities.

Weinstein, Carol Simon. 1979. "The physical environment of the school: A review of research." Review of Educational Research 49 (4):577-610.

Weinstein, Carol Simon, Andrew J Mignano, and Molly E Romano. 2011. Elementary classroom management: Lessons from research and practice: McGraw-Hill New York.

Winter, Eileen, and P. O'Raw. 2010. Literature review of the principles and practices relating to inclusive education for children with special educational needs. Trim, Northern Ireland: National Council for Special Education.

World Health Organization. 2004. The physical school environment: An essential element of a health-promoting school. edited by Department of Protection of the Human Environment and the Department of Noncommunicable Disease Prevention and Health Promotion. Geneva: WHO. 
Table 1. Demographic characteristics of teachers at the selected inclusive schools

\begin{tabular}{|c|c|c|}
\hline Demographics & Frequency(n) & Percentage (\%) \\
\hline \multicolumn{3}{|l|}{ Gender } \\
\hline Male & 64 & 39.0 \\
\hline Female & 100 & 61.0 \\
\hline \multicolumn{3}{|l|}{ Age (years) } \\
\hline $25-30$ & 74 & 45.1 \\
\hline $31-35$ & 20 & 12.2 \\
\hline $36-40$ & 12 & 7.3 \\
\hline $41-45$ & 30 & 18.3 \\
\hline $46+$ & 28 & 17.1 \\
\hline \multicolumn{3}{|l|}{ Qualification } \\
\hline 3 -Year Cert ' $A$ '* & 68 & 41.5 \\
\hline Diploma in Education & 38 & 23.2 \\
\hline Degree in Education & 52 & 31.7 \\
\hline Degree in Special Education & 4 & 2.4 \\
\hline Master's Degree in Education & 2 & 1.2 \\
\hline \multicolumn{3}{|l|}{ Teaching Experience (years) } \\
\hline $1-5$ & 94 & 57.3 \\
\hline $6-10$ & 30 & 18.3 \\
\hline $11+$ & 40 & 24.4 \\
\hline
\end{tabular}

*Teachers were undertaking various courses leading to diploma and degree in education 
Table 2. Physical environment of inclusive schools $(\mathrm{N}=164)$

\begin{tabular}{llc}
\hline Nature of physical environment & Good (\%) & Poor (\%) \\
\hline Ventilation in classrooms and other buildings & $89(54.3)$ & $75(45.7)$ \\
Natural and artificial illumination in classrooms and other buildings & $70(43.0)$ & $94(57.0)$ \\
Seating arrangement in classrooms & $72(43.9)$ & $92(56.1)$ \\
Decorations, paintings and colour in classrooms and buildings & $66(40.0)$ & $98(60.0)$ \\
Classroom facilities (e.g., bookshelves and notice boards) and their use & $44(26.8)$ & $120(73.2)$ \\
by children with disability & $60(36.6)$ & $104(63.4)$ \\
School compound, and the safety and comfort of children with disability & $50(30.5)$ & $114(69.5)$ \\
School compound and movement of children with disability & $54(33.0)$ & $110(67.0)$ \\
Spaces in classrooms and use of school facilities (e.g., washroom, toilet \& urinal)
\end{tabular}

Table 3. Accessibility of the physical environment of inclusive schools

\begin{tabular}{lcc}
\hline Accessibility & Frequency (n) & Percentage (\%) \\
\hline Accessible & 64 & $39.0 \%$ \\
Less accessible & 100 & $61.0 \%$ \\
\hline Total & 164 & $100.0 \%$ \\
\hline
\end{tabular}


Table 4. Suitability of the physical environment for physical activities $(\mathrm{N}=164)$

\begin{tabular}{lcc}
\hline Suitability & Frequency (n) & Percentage (\%) \\
\hline Suitable & 66 & $40.0 \%$ \\
Less suitable & 98 & $60.0 \%$ \\
\hline Total & 164 & $100.0 \%$ \\
\hline
\end{tabular}

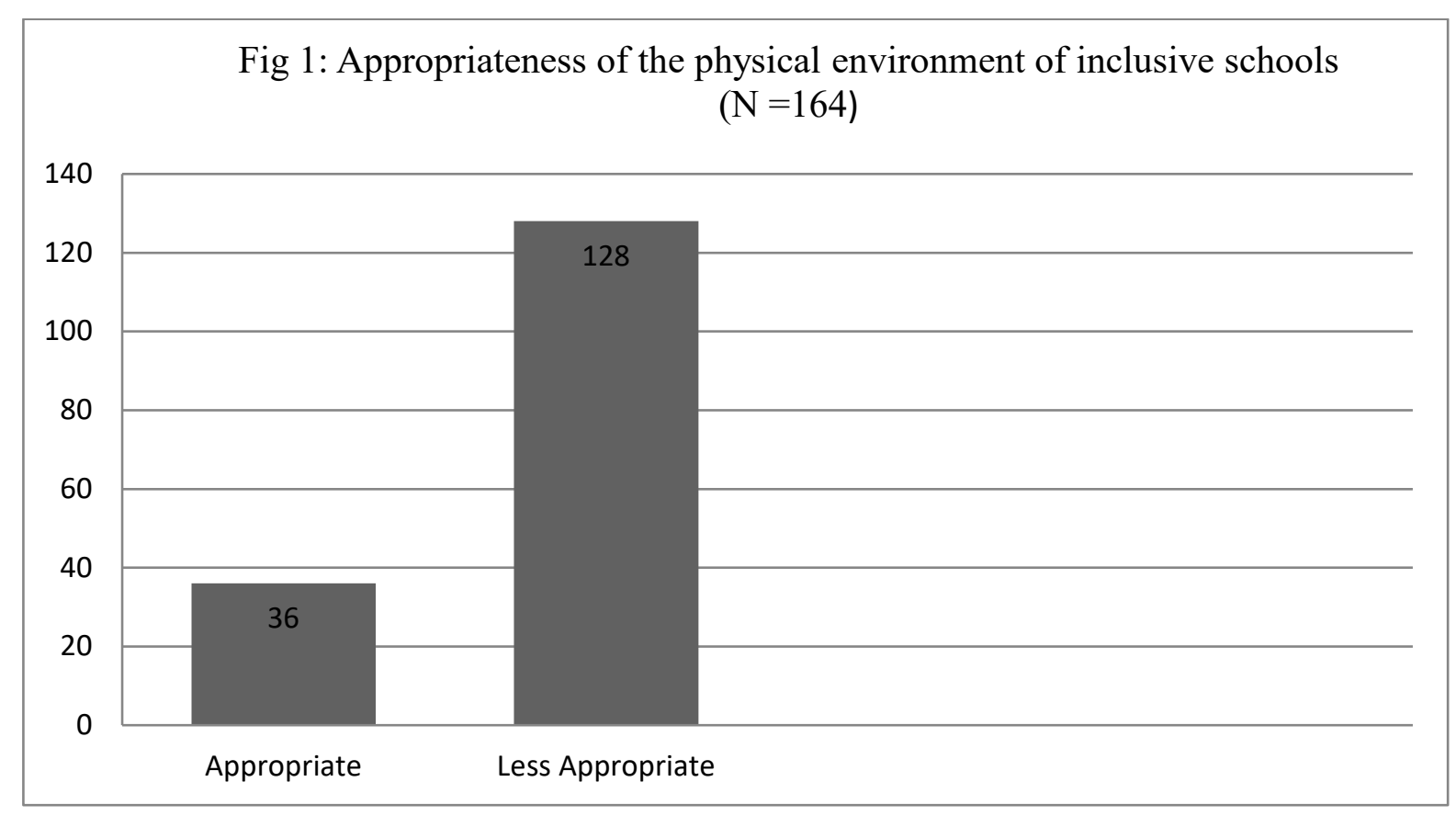

